\title{
Adubo a partir de lodo de esgoto industrial: produção e viabilidade para a cultura do feijoeiro
}

Devido ao crescimento industrial elevado, faz-se necessário o estudo do papel da indústria em relação à geração de resíduos sólidos, efluentes e a emissão de resíduos atmosféricos. Desse modo, o presente trabalho teve como objetivo geral implantar o processo de produção do adubo orgânico a partir do lodo de ETE em uma indústria de Paraipaba, Ceará, tendo como objetivos específicos: demonstrar as etapas de produção do adubo a partir do lodo de ETE da indústria Paraipaba Agroindustrial, avaliar o processo de produção de adubo, e analisar a influência do adubo na emergência de plântulas de Vigna unguiculata (I.) Walp. (feijão-de-corda). Foram plantadas 50 sementes de feijão-de-corda, distribuídas entre dois tratamentos: solo com adubação e solo sem adubação. Os tratamentos foram submetidos às mesmas condições de temperatura e irrigação, sendo acompanhados diariamente durante sete dias. $O$ processo de formação do e solo sem adubação. Os tratamentos foram submetidos às mesmas condições de temperatura e irrigação, sendo acompanhados diariamente durante sete dias. O processo de formação do para a retirada de resíduos dos tratamentos anteriores e obtido o adubo seco e de boa qualidade pronto para ser empregado na agricultura. Durante os sete dias de tratamento, não fo obtida nenhuma plântula de feijão emergida no tratamento do solo sem adubação. Quanto ao tratamento com adubação, $36 \%$ das sementes emergiram. As doses de adubo proveniente do lodo de esgoto aumentaram a emergência de plântulas do feijão-de-corda, demonstrando que serve como substrato para aplicação na agricultura.

\section{Industrial sewage sludge as fertilizer: production and feasibility for the bean culture}

Due to the high industrial growth, it is necessary to study the role of the industry in relation to the generation of solid waste, effluents and the emission of atmospheric waste. Thus, the present work had as general aim to implant the production process of an organic fertilizer from the ETE sludge in an industry of Paraipaba, Ceará. As specific aims: to demonstrate the stages of production of the fertilizer from the ETE sludge from the Paraipaba Agroindustrial industry, evaluate the fertilizer production process, and analyze the influence of fertilizer on the emergence of seedlings of Vigna unguiculata (I.) Walp. (string beans). Fifty cowpea seeds were planted, distributed between two treatments: soil with fertilization and soil without fertilization. The treatments were submitted to the same conditions of temperature and irrigation, being monitored daily for seven days. The fertilizer formation process was divided into four stages: filtration of the coarse effluent, treatment of the effluent, obtaining the sludge and obtaining the fertilizer. At the end of the drying step, a sieve was removed to remove residues from the previous treatments and a good quality dry fertilizer was obtained, ready to be used in agriculture. During the seven days of treatment, no bean seedling emerged from the soil treatment without fertilization was obtained. As for the treatment with fertilization, $36 \%$ of the seeds emerged. The doses of fertilizer from the sewage sludge increased the emergence of cord bean seedlings, demonstrating that it serves as a substrate for application in agriculture.

Keywords: Agricultural production; Effluent; Seedlings emergence; Organic matter.

Topic: Engenharia Agrícola

Reviewed anonymously in the process of blind peer
Received: 02/01/2021

Approved: 25/01/2021
Lucas Santana de Morais (iD)

Centro Universitário Terra Nordeste, Brasil

http://lattes.cnpq.br/3551521892326295

http://orcid.org/0000-0002-9251-998X

llucas.ssantana@gmail.com

Fernando Weslley Silva de Oliveira (i)

Universidade Federal de Santa Catarina, Brasil

http://lattes.cnpq.br/1519476959062466

http://orcid.org/0000-0003-0916-3546

fwsoliver@gmail.com

Ivan Jeferson Sampaio Diogo (iD

Instituto Federal da Paraíba, Brasil

http://lattes.cnpq.br/2967663849441382

http://orcid.org/0000-0002-5440-9851

ivan.diogo@ifpb.edu.br
Referencing this:

MORAIS, L. S.; OLIVEIRA, F. W. S.; DIOGO, I. J. S.. Adubo a partir de lodo de esgoto industrial: produção e viabilidade para a cultura do feijoeiro. Revista Ibero Americana de Ciências Ambientais, v.12, n.1, p.42-53, 2021. DOI: http://doi.org/10.6008/CBPC21796858.2021.001.0005 


\section{INTRODUÇÃO}

Estações de tratamento de efluentes (ETE) têm como objetivo a remoção de poluentes presentes dentro do rejeito líquido gerado pela área urbana (doméstica) ou de indústrias, e fazem com que os nutrientes e matéria orgânica presentes nas águas residuais retornem ao meio ambiente de forma inadequada e sem o seu devido tratamento adequado. A produção de lodo em uma ETE corresponde a cerca de 1 a $2 \%$ do efluente tratado, no entanto o tratamento e a disposição final desse resíduo podem atingir de 30 a 50\% do custo operacional da estação (SUCIU et al., 2015).

Produzir adubo a partir de lodo de ETE não é uma tarefa tão difícil de ser empregada na indústria. Com a utilização do rejeito gerado a partir do tratamento do efluente industrial, pode se obter um material de altas concentrações de material orgânico (adubo), que poderá ser empregado diretamente na produção agrícola, podendo gerar um alto potencial produtivo às culturas, além de reforçar o solo quando o mesmo precisa ser recuperado (NOGUEIRA et al., 2008).

Várias pesquisas desenvolveram estudos sobre uso do lodo de esgoto em culturas agrícolas e no plantio de árvores (JUNIO et al., 2011; 2013; NASCIMENTO et al., 2014). A partir dessa produção de adubo, a empresa geradora de resíduos gera uma grande economia porque ao invés de gastar dinheiro com a remoção deste lodo gerado, pode investir em equipamentos e no treinamento e formação de pessoas para saber tratar e transformar lodo em adubo.

De acordo com Andreoli et al. (2000), a produção de adubo a partir de lodo de ETE reduz a utilização de produtos químicos artificiais que poderiam vir a ser empregados ao solo. A utilização excessiva desses produtos químicos poderia causar uma saturação neste solo e o transformar em infértil. De modo contrário, com a utilização do adubo, haverá uma interação mais intrínseca entre o solo, o adubo e a planta, proporcionando um solo rico em matéria orgânica e com disponibilidade de ceder nutrientes necessários para a produção agrícola (BARBOSA et al., 2007).

O adubo orgânico propicia melhoria das características químicas, físicas e biológicas do solo, melhorando a retenção de água, aumentando a porosidade e consequentemente facilitando a drenagem, evitando com isso o escorrimento superficial. Além disso, a incorporação do adubo disponibiliza nutrientes para as plantas e melhora a sanidade e o desenvolvimento radicular, contribuindo para o desenvolvimento integral da planta. Dessa forma, há uma promoção de reciclagem de resíduos orgânicos, evitando a contaminação ambiental (CAMPOS et al., 2008).

Devido ao crescimento industrial elevado, faz-se necessário o estudo do papel da indústria em relação à geração de resíduos sólidos e efluentes, além da emissão de resíduos atmosféricos. É de fundamental importância que empresas e indústrias do terceiro setor tenham responsabilidade ambiental. Nesse contexto, vale salientar a importância de se estabelecer alternativas para a disposição final do lodo de esgoto, uma vez que esse pode vir a contaminar lençóis freáticos quando depositados diretamente em aterro sanitário, por exemplo. 
Portanto, objetivou-se com este trabalho implantar o processo de produção de adubo a partir de lodo de ETE de uma indústria de Paraipaba, Ceará. Tendo como objetivos específicos: a) demonstrar as etapas de produção do adubo a partir do lodo de ETE, b) avaliar o processo de produção de adubo, e c) analisar a influência do adubo na emergência de plântulas de Vigna unguiculata (I.) Walp. (feijão-de-corda).

\section{REVISÃO TEÓRICA}

\section{Estação de tratamento de efluente (ETE)}

Toda indústria tem como consequência de sua produção a geração de grandes quantidades de resíduos, resíduos esses que deverão ser reprocessados de forma correta para não serem depositados no meio ambiente de qualquer forma. Um dos principais resíduos gerado pela indústria é o efluente de tratamento industrial, que é produzido através de todos os processos produtivos industriais, gerando assim grandes quantidades, necessitando de um tratamento adequado de acordo com o efluente gerado (SOUZA et al., 2012).

O tratamento em uma ETE pode-se utilizar de vários agentes químicos durante seu processo em diferentes etapas, dentre eles: agentes de coagulação, neutralização de $\mathrm{PH}$, oxirredução, floculação e desinfecção. Dessa forma, ocorre a remoção dos poluentes por meio de reações químicas, além de proporcionar o condicionamento da mistura de efluentes produzida que será tratada nas etapas posteriores (PEDROZA et al., 2010).

O efluente industrial é o resultado da utilização de água, pelas indústrias, em seus processos, como na lavagem de máquinas, tubulações, sistemas de resfriamento, e diretamente no produto. Por isso, os efluentes industriais variam de acordo com cada tipo de produção nas empresas e podem conter óleos diversos, metais pesados, entre outras substâncias altamente contaminantes e tóxicas (CAVALCANTE, 2015).

Existem várias estações de tratamento de efluentes (ETE) espalhadas pelo Brasil com o objetivo de diminuir a quantidade de poluentes do efluente antes de despejá-lo na natureza. Parte desses efluentes, tanto domésticos quanto industriais, é lançada novamente ao meio ambiente e, portanto, precisa ser tratado para não contaminar o solo e os mares. Duas das principais características dos efluentes são o odor e a cor, que são desagradáveis para os seres humanos, além do caráter perigoso das substâncias (MELO et al., 2004).

De acordo com Cavalcante (2015), o tratamento de esgoto consiste basicamente da utilização de processos físicos, químicos e biológicos, que resultam na remoção dos sólidos presentes no meio, e da matéria orgânica resultante da utilização da água no processo produtivo das indústrias, efluente esse que será tratado com a remoção de todas as impurezas toxicas presentes que poderão agredir o solo, logo após com a utilização desse efluente tratado.

Mesmo assim, esse ainda apresenta grande quantidade de matéria orgânica presente, que será obtida através de filtros artesanais e a utilização do sol para secar o lodo gerado e tendo um lodo seco, próprio para ser lançado no solo, com suas devidas quantidades. Resultados de pesquisas indicam que o lodo 
de esgoto é rico em nitrogênio, fósforo e micronutrientes, apresenta teores de umidade variável e alta concentração de matéria orgânica (BARBOSA et al., 2007).

\section{Influência do lodo de esgoto nas características do solo}

A utilização do lodo de esgoto de ETE é considerada benéfica em relação as suas propriedades química, física e biológica, que serão aproveitadas como fertilizante e condicionador do solo envolvendo práticas de reciclagem agrícola, recuperação de áreas degradadas, substrato para a produção de mudas, entre outras (SILVA, 2008; KITAMURA et al., 2008).

Um dos principais feitos da matéria orgânica sobre os atributos físicos do solo, está associado ao grau de agregação, que consequentemente, afeta a densidade, porosidade, aeração e a capacidade de retenção e infiltração de água (BARBOSA et al., 2007). Por outro lado, os principais efeitos nos atributos químicos são aumento no teor de matéria orgânica com aumento na CTC (MELO et al., 2000). Quintana et al. (2009) demonstrou que adicionar matéria orgânica no solo pode estimular a decomposição devido ao aumento da população de microrganismos, que produz as enzimas que atacam a matéria orgânica nativa do solo, ocasionando perdas de carbono.

Produzindo o resíduo sólido em quantidade e composição variáveis de acordo com as características dos efluentes e dos processos de tratamento adotados. O controle sobre a qualidade dos tipos de efluentes lançados na rede coletora é imprescindível para que o lodo gerado possa ser utilizado na agricultura.

A maior disponibilidade de nutrientes no solo decorrente da aplicação de lodo de esgoto pode levar a um melhor desenvolvimento da planta e consequentemente maior produtividade das culturas. Entretanto, em função da composição do lodo, nem sempre é mantido o equilíbrio adequado entre os diferentes nutrientes, de modo que, mesmo havendo aumento na disponibilidade de alguns nutrientes, a planta poderá não responder (TAMANINI et al., 2008). O efeito do lodo de esgoto na produtividade vem sendo avaliado em diversas condições, doses, tipo de material, solo e culturas.

Aplicação do adubo obtido por meio do lodo de ETE na produção agrícola

O lodo de esgoto não deve ser aplicado diretamente nas áreas agrícolas ou florestais sem te sido submetido preliminarmente a tratamentos biológicos que reduzam sua carga orgânica e promova a estabilização do material. O lodo cru que não tenha recebido tratamento adequado para controle de poluentes e patógenos não é considerado benéfico para o solo (CARRINGTON, 2001).

É notório que devido sua alta concentração de matéria orgânica, o lodo de esgoto compõe importante incremento para a fertilidade do solo, oferecendo a planta os nutrientes de que ela necessita, consequentemente, contribui para o aumento e desenvolvimento da produção agrícola, sendo dispensável muitas vezes o uso de fertilizantes, o que acarreta em menos gastos para o produtor rural e ainda colabora com a manutenção do meio ambiente (BETTIOl et al., 2006; NOGUEIRA et al., 2008).

Com a produção do adubo, obtido através da utilização do lodo de ETE, que foi seco ao ar, pode se então ter um substrato de fortes propriedades que irão auxiliar na agricultura, tanto na recuperação de áreas degradadas como diretamente na produção agrícola. A aplicação do adubo precisa ser analisada tanto sob o 
ponto de vista agrícola e, por se tratar de um resíduo rico em matéria orgânica e nutrientes, como pelos aspectos sanitário, legal, ambiental e econômico. A disposição em áreas agricultáveis é ainda considerada problemática em função da escassez de informações com relação à capacidade de suporte do solo (QUINTANA et al., 2011).

Desse modo, a aplicação do adubo em áreas cultivadas com fruteiras tropicais, café, silvicultura, dentre outras, deve ser avaliada de forma criteriosa sendo fundamental o conhecimento do impacto causado no meio ambiente pela sua utilização, bem como o desenvolvimento de tecnologias que permitam a inserção do adubo de forma adequada nos sistemas agrícolas. Como um dos principais problemas na agricultura é a baixa disponibilidade de matéria orgânica para o plantio e condução das lavouras comerciais, o uso desse adubo poderá minimizar este problema, além de possibilitar, de maneira inovadora, a gestão dos resíduos sólidos gerados no tratamento de efluentes industriais (ANDREOLI et al., 2014).

Nesse sentido, lodos de esgoto têm sido utilizados como fertilizante agrícola para aumentar a produtividade de diversas culturas (LATARE et al., 2014, SUCIU et al., 2015), uma vez que possuem matériaprima de elevado potencial agronômico, rica em matéria orgânica e nutrientes, como nitrogênio, potássio e fósforo (TAMANINI et al., 2008).

\section{METODOLOGIA}

\section{Área de estudo}

O município de Paraipaba localiza-se ao norte do estado do Ceará a cerca de $115 \mathrm{Km}$ da capital de Fortaleza, nas coordenadas geográficas de Latitude: -3,4648105 e Longitude: -39,2007221. O município faz fronteira com os municípios de Trairi, São Gonçalo do Amarante e Paracuru e possui zona litorânea. Com temperatura média anual situando-se entre 26 e $27^{\circ} \mathrm{C}$, mínima de $19^{\circ} \mathrm{C}$ e máxima de $29^{\circ} \mathrm{C}$, o município apresenta uma pluviometria média histórica em torno de $1.200 \mathrm{~mm} /$ ano e sua sede encontra-se a $26 \mathrm{~m}$ de altitude com relação ao nível do mar (FUNCEME, 2010).

A indústria estudada é responsável por trabalhar diretamente com a produção de água de coco e possui estação de tratamento de esgoto com diferentes fases e tratamentos químicos. Os tratamentos envolvem: peneiração hidrostática, tanques de elevatórios 1 e 2, tanque de bactérias, tanques de decantação 1 e 2, filtro de areia, tanque de rejeito e tanque do lodo. No entanto, não há produção de adubo a partir do lodo da ETE.

Desse modo, foi gerado um plano de trabalho para implantação de tratamentos químicos, físicos e biológicos que pudessem ser utilizados para a produção de adubo orgânico a partir dos efluentes industriais e resíduos dos processos produtivos da indústria. Esse adubo auxiliaria no processo de produção agrícola na própria indústria, sendo ainda uma opção sustentável para utilização em projetos socioambientais. 


\section{Análise de dados}

Para atingir os objetivos propostos, realizou-se um estudo com abordagem qualitativa e descritiva. Foram monitoradas, descritas e fotografadas cada etapa do processo de tratamento do lodo e transformação em adubo com a finalidade de demonstrar e discutir o processo.

Foram plantadas 100 sementes de feijão-de-corda (Vigna unguiculata), distribuídas entre dois tratamentos: solo com adubação e solo sem adubação. Os tratamentos foram submetidos às mesmas condições de temperatura e irrigação, sendo acompanhados diariamente durante trinta dias. Os tratamentos foram distribuídos em delineamento de blocos casualizados em esquema fatorial 2 × 2 (com e sem adubação), com 5 repetições de 20 sementes em cada.

Posteriormente, foram calculadas as porcentagens de emergência, o tempo médio de emergência e o índice de velocidade de emergência (IVE) (MAGUIRE, 1962) das plântulas de milho e feijão-de-corda nos dois tratamentos. O índice foi calculado a partir dos dados de contagem diária de plântulas emersas. Para fins de contagem, considerou-se como plântulas emergidas somente aquelas cujos cotilédones estivessem abertos. O IVE é dado pela Equação (1):

$$
\text { (1) IVE }=N 1 / D 1+N 2 / D 2+\ldots .+N n / D n \text {, }
$$

Onde $\mathrm{N}=$ número de plântulas emergidas observadas no dia da contagem e $\mathrm{D}=$ número de dias após a semeadura em que foi feita a contagem de plântulas (MAGUIRE, 1962).

\section{RESULTADOS E DISCUSSÃO}

O processo de formação do adubo foi dividido em quatro etapas para melhor caracterizá-lo: filtração do efluente bruto, tratamento do efluente, obtenção do lodo e obtenção do adubo.

\section{Filtração do efluente bruto}

Foram utilizados os seguintes materiais: Três tambores de 200 litros, três flanges de 40mm, três curvas de $40 \mathrm{~mm}$, dois T de $40 \mathrm{~mm}, 6$ metros de cano de 40mm, carvão ativado, areia grossa, pedrisco e brita grossa (Figura 1). Todos esses materiais foram empregados nos tambores de forma que os três ficassem interligados com a finalidade de aumentar a vazão do efluente filtrado, assim podendo se obter uma quantidade maior de lodo gerado (Figura 2).

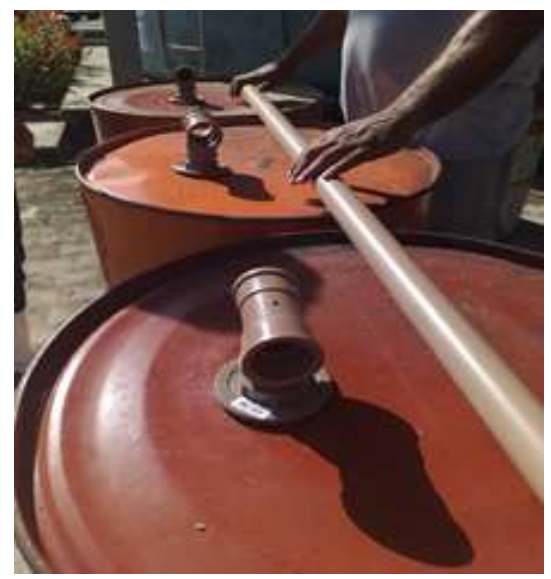

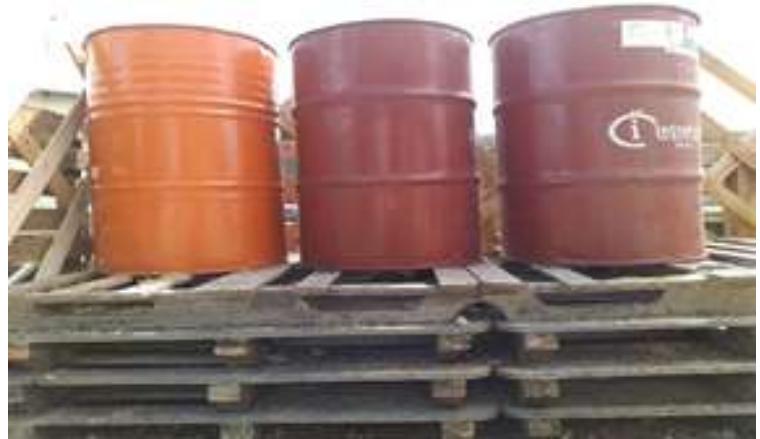

Figura 2: Tambores seccionados através de canos.

Figura 1: Processo de interligação entre os tambores. 


\section{Tratamento do efluente}

Quando o efluente industrial chega à estação de tratamento, ele é submetido a três distintos tratamentos: físico, químico e biológico. Ao passar pelo físico, são retirados todos os resíduos macroscópicos através de uma peneira hidrostática, a qual irá segregar os sólidos presentes. Em seguida, encaminha-se para o tratamento químico, onde há a adição de componentes que irão retirar os metais pesados solúveis. Por fim, segue para o tratamento biológico, no qual são inseridas substâncias floculadoras que absorvem a matéria orgânica, decantando ao fundo do tanque de floculação (Figura 3 a, b).
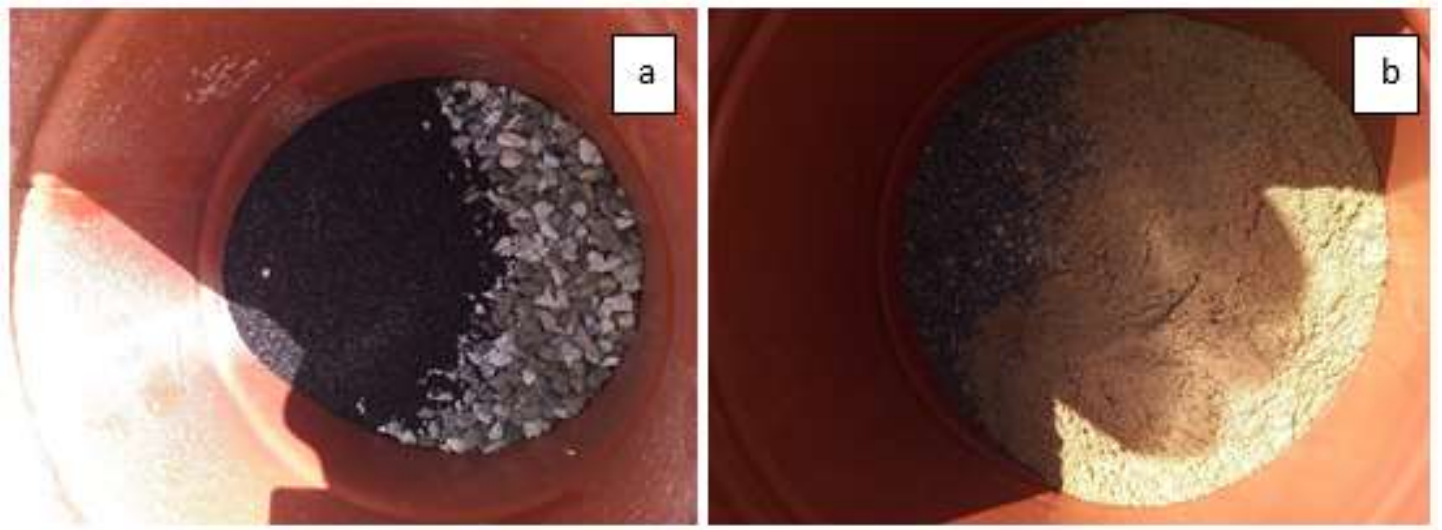

Figura 3: a) Camadas de brita grossa e de carvão ativado, b) camadas de pedrisco e areia grossa.

\section{Obtenção do lodo}

Com a ajuda de um motor hidráulico, foi possível inserir nos tambores o efluente para a produção do lodo (Figura 4). O sistema filtrante mostrou-se bastante eficiente, fazendo com que partículas maiores ficassem retidas nos filtros, tendo praticamente dois produtos finais, uma água limpa e praticamente isenta de odor e uma grande quantidade de lodo (Figura 5).

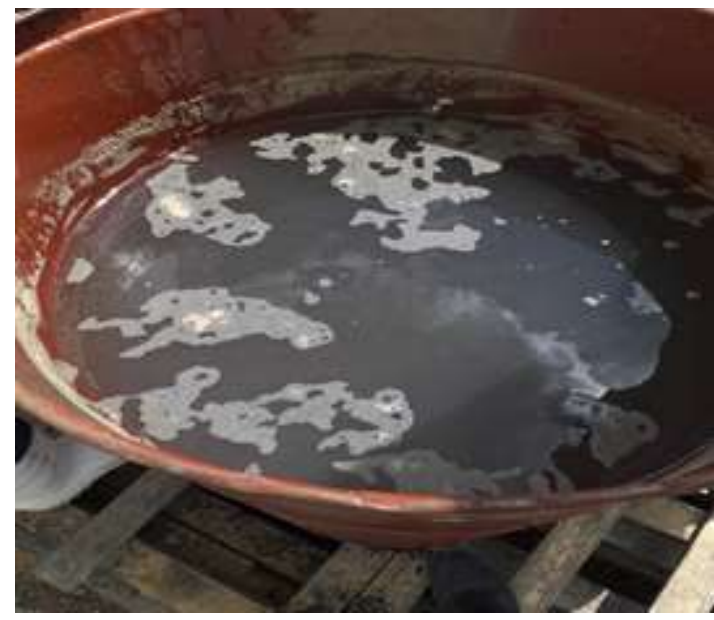

Figura 4: Efluente inserido no sistema de filtros.

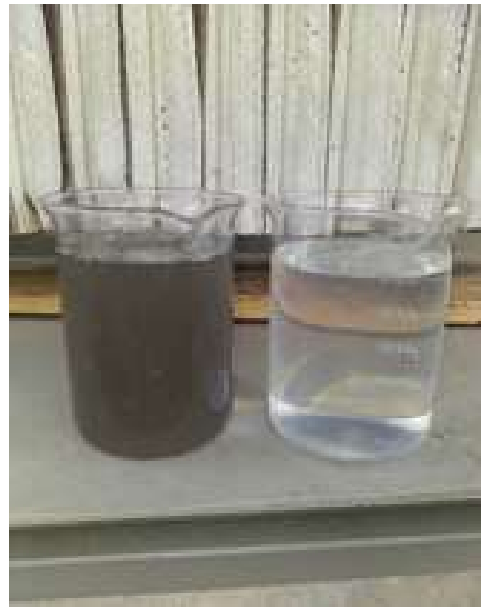

Figura 5: Água pré e pós-sistema filtrante.

Enquanto a parte líquida, a água residual, é empregada em processos de irrigação e experimentos agrícolas na própria indústria, a parte sólida é removida para tratamento e disposição final. Algumas das partes separadas durante o tratamento de esgoto são areia, os sólidos retidos no gradeamento e o lodo. Destes, o lodo é o que é gerado em maior quantidade e sua destinação a mais preocupante, uma vez que sua 
disposição irregular pode trazer consequências ambientais (METCALF et al., 2003). Com a filtração e a decantação de todo o material, obteve-se ao fundo de cada tambor quantidades consideráveis de matéria orgânica, ou seja, de lodo.

\section{Obtenção do adubo}

O lodo foi recolhido (Figura 6) e destinado para um local em que fosse exposto ao sol, para que fosse seco ao ar (Figura 7), a medida em que a água era evaporada era feito o revolvimento deste lodo para que o processo de secagem pudesse ser eficiente. Ao final da etapa de secagem, foi feito uma peneiragem para a retirada de resíduos dos tratamentos anteriores. Depois desse processo, obteve-se o adubo seco para ser testado na agricultura (Figura 8) e posteriormente aplicado no experimento com o feijão-de-corda.

Apesar de rico em matéria orgânica e em nutrientes como nitrogênio, fósforo e micronutrientes, a Resolução CONAMA no 375 (CONAMA, 2006) não permite que este resíduo seja utilizado diretamente no solo para cultivo agrícola, por conterem organismos que possuem com potencial patogênico. O nível destes microrganismos necessita ser reduzido a níveis que não tragam riscos à saúde pública.

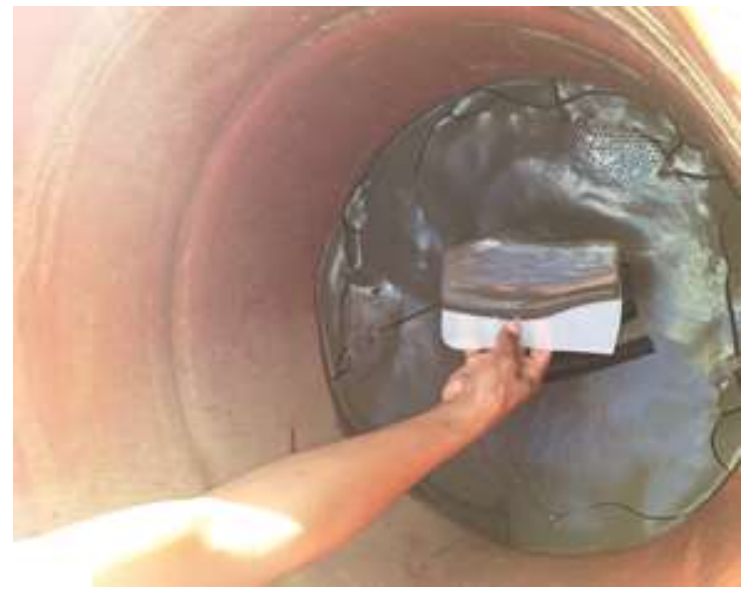

Figura 6: Recolhimento do lodo decantado.

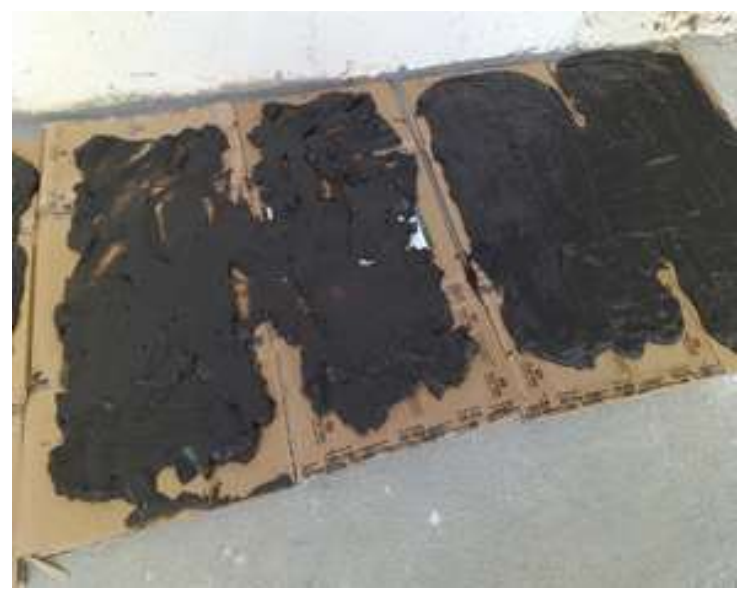

Figura 7: Processo de secagem térmica do lodo.

Por isso, faz-se necessário submeter o resíduo gerado a um processo de estabilização, secagem e higienização. As principais formas de higienização do lodo são a adição de cal, compostagem e secagem térmica (ANDREOLI et al., 2014). A forma abordada nesse estudo envolveu a compostagem e a secagem térmica, sendo a forma mais econômica e rápida para o processo de produção do adubo, uma vez que se estuda empregar o processo como um todo na viabilidade da indústria.

Utilizar o lodo como fertilizante agrícola propõe uma maneira de agregar valor econômico ao resíduo, tornando-o comercial. Dessa forma, podemos observar que a técnica desenvolvida nesse trabalho é viável e rentável para a indústria e, consequentemente, para o meio ambiente. Lemainski et al. (2006) apontam que esta é a opção mais promissora dentre as existentes de disposição ou incineração.

Guedes et al. (2006) afirma que utilizar o lodo de esgoto como biofertilizante e condicionador de solos permite ganhos econômicos a quem está produzindo. Além disso, pode gerar um aumento da produtividade das culturas e redução do uso de fertilizantes minerais, contribuindo para a conservação ambiental pela efetivação de métodos adequados e mais econômicos de disposição final desse resíduo. No 
entanto, para que os solos possam receber aplicação de adubo proveniente de lodo de esgotos, devem obedecer à legislação vigente, e respeitar a proximidade de áreas residenciais, a direção predominante de ventos e a declividade mínima da área (TSUTIYA, 2001).

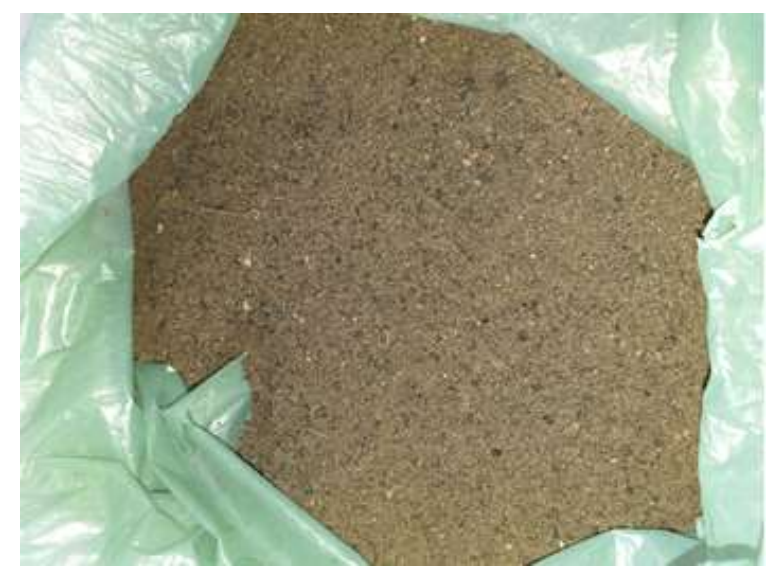

Figura 8: Adubo seco e acondicionado para a utilização na agricultura.

\section{Emergência de plântula de feijão-de corda com o adubo obtido}

Durante os 15 dias dos tratamentos, foram obtidas 3 plântulas (3\%) emergidas no tratamento do solo sem adubação. Quanto ao tratamento com adubação, 56\% das sementes emergiram (56 plântulas). No tratamento sem adubação, as plântulas começaram a emergir no dia sete e estabilizaram no dia nove. Já, as plântulas com a adubação começaram a emergir ao terceiro dia e estabilizaram no oitavo dia (Figura 9), obtendo um índice de velocidade de emergência de 14,98 sementes/dia e tempo médio de emergência de 2,14 dias.

Esses resultados demonstram que a utilização do adubo produzido na estação de tratamento da empresa obteve resposta positiva, no entanto não se pôde realizar um teste estatístico comparativo porque não há variância entre os dados de emergência de solo sem adubação.

Nascimento et al. (2004) encontraram que plantas de feijoeiro e de milho cultivadas em casa de vegetação responderam positiva e significativamente às doses de lodo adicionadas no solo, tanto em matéria seca quanto em germinação. As aplicações de doses crescentes de lodo de esgoto promoveram diminuição do $\mathrm{pH}$ e aumento nos teores de matéria orgânica, nitrogênio total, fósforo, potássio, sódio, cálcio e magnésio dos solos, influenciando positivamente os cultivares. Maciel et al. (2009) observaram que o lodo de ETE industrial foi eficiente para o desenvolvimento das mudas de espécie vegetal feijoeiro (Phaseolus vulgares).

Trannin et al. (2005) observou que o lodo de esgoto melhorou a fertilidade do solo, o estado nutricional e a produtividade do milho. Além de cultivares agrícolas, o lodo de esgoto influenciou positivamente no incremento da biomassa aérea e radicular de espécies arbóreas (TRIGUEIRO et al., 2014). Zomer et al. (2018) encontraram que as plantas com adubação mineral e lodo de ETE em culturas de aveia e fumo apresentaram desenvolvimento semelhante, com plantas saudáveis, ao contrário das plantas sem adubação, que se desenvolveram de forma inferior. 


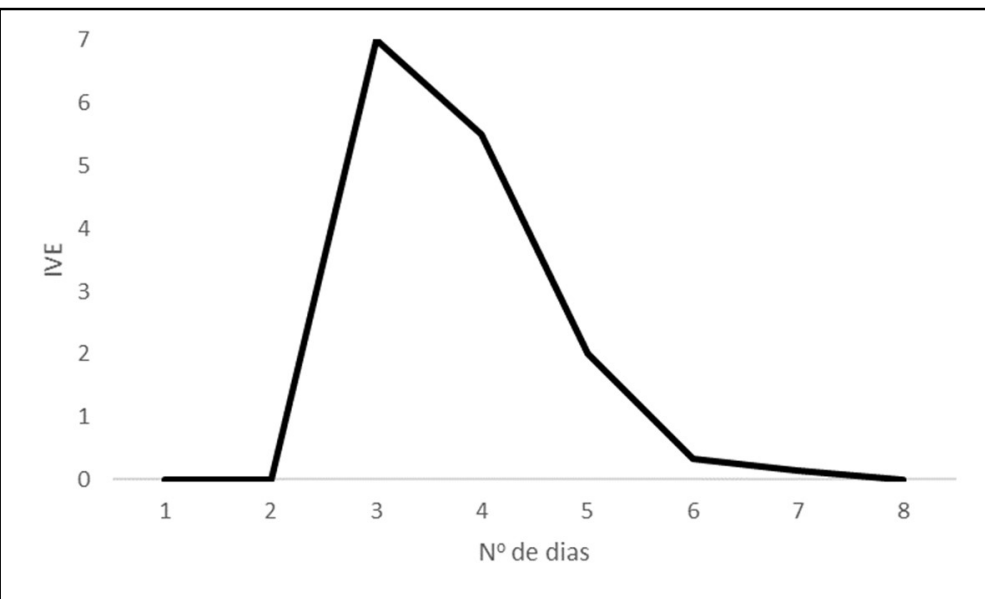

Figura 9: Índice de velocidade de emergência (IVE) de sementes de feijão-de-corda adubada com adubo produzido a partir de lodo de ETE.

O adubo proveniente do lodo de esgoto da indústria estudada provocou um aumento na germinação de sementes com posterior emergência de plântulas, mostrando que se deve investir na reutilização do lodo de esgoto proveniente de indústrias. Além disso, a sequência de etapas e processos demonstradas nesse estudo garantem um processo simples e prático para obtenção do adubo.

\section{CONCLUSÕES}

Ao abordar o tema, procurou-se mostrar interesse no tratamento do lodo produzido na indústria pela notoriedade do grande volume de efluente gerado. A secagem térmica do lodo de esgoto na estação de tratamento da indústria mostrou-se economicamente viável face ao custo de manutenção e disposição final do adubo. Além disso, evita riscos ao meio ambiente por descarte aterros sanitários.

As doses de adubo proveniente do lodo de esgoto aumentaram a emergência de plântulas do feijãode-corda, demonstrando que serve como substrato para aplicação na agricultura. Daí o interesse da utilização dessa matéria orgânica na produção de adubo seco.

De acordo com o experimento realizado, pode-se notar que o adubo tem uma alta quantidade de matéria orgânica que serve de um valor de substrato para planta fazendo com que a mesma possa se desenvolver em uma rapidez mais elevada do que ela plantada somente no solo. A isso, leva-se em conta todo o processo de decomposição da matéria orgânica presente no adubo seco pronto para utilização, tanto na composição do solo, quanto na nutrição de plantas.

Apesar dos benefícios claros da aplicação de adubo proveniente de lodo de esgoto, deve-se monitorar o biossólido produzido em relação aos nitratos, metais pesados, compostos orgânicos persistentes e patógenos humanos. Quando os parâmetros do lodo de esgoto estiverem enquadrados nas normas específicas, pode ser aplicado na agricultura.

\section{REFERÊNCIAS}

ANDREOLI, C. V.; PEGORINI, E. S.. Gestão pública do uso agrícola do lodo de esgoto. In: BETTIOL, W.; CAMARGO, O.

A.. Impacto ambiental do uso agrícola do lodo de esgoto. Jaguariúna: Embrapa Meio Ambiente, 2000. p.281-312.
ANDREOLI, C. V.; SPERLING, M. V.; ANDREOLI, C. V.. Lodos de esgoto: tratamento e disposição final. 4 ed. Belo Horizonte: UFMG, 2014.

BARBOSA, G. M. C.; TAVARES FILHO, J.; FONSECA, I. C. B.. 
Efeito do lodo de esgoto em propriedades físicas de um Latossolo Vermelho eutroférrico. Semina: Ciências Agrárias, v.28, n.1, p.65-70, 2007. DOI: http://doi.org/10.5433/1679$\underline{0359.2007 v 28 n 1 p 65}$

BETTIOL, W.; CAMARGO, O. A.. A disposição de lodo de esgoto em solo agrícola. In: BETTIOL, W.; CAMARGO, O. A.. Lodo de esgoto: 115 impactos ambientais na agricultura. Jaguariúna: Embrapa Meio Ambiente, 2006. p.17-24.

CAMPOS, F. S.; ALVES, M. C.. Uso de lodo de esgoto na reestruturação de solo degradado. Revista Brasileira de Ciências do Solo, v.32, n.4, p.1389-1397, 2008. DOI: http://doi.org/10.1590/S0100-6832008000400003

CAVALCANTE, K. D. B.. O Uso de Águas Residuais e as Vantagens de sua Aplicação na Agricultura. Monografia (Bacharelado) - Universidade Estadual da Paraíba, João Pessoa, 2015.

CARRINGTON, E. G.. Evaluation of sludge treatments for pathogen reduction. Final Report. Report $n^{\circ} 5026 / 1$. Luxembourg: Office for Official Publications of the European Communities, 2001.

CONAMA. Conselho Nacional do Meio Ambiente. Resolução $n^{\circ} 375$, de 29 de agosto de 2006: Define critérios e procedimentos, para o uso agrícola de lodos de esgoto gerados em estações de tratamento de esgoto sanitário e seus produtos derivados, e dá outras providências. Brasília: MMA, 2006.

FUNCEME. Fundação Cearense de Meteorologia e Recursos Hídricos. Postos pluviométricos. FUNCEME, 2010.

GUEDES, M. C.; ANDRADE, C. A.; POGGIANI, F.; MATTIAZZO, M. E.. Propriedades químicas do solo e nutrição do eucalipto em função da aplicação de lodo de esgoto. Revista Brasileira de Ciência do Solo, v.30, p.267-280, 2006. DOI: http://doi.org/10.1590/\$0100-06832006000200008

JUNIO, G. R. Z.; SAMPAIO, R. A.; SANTOS, G. B.; NASCIMENTO, A. L.; PRATES, F. B.; FERNANDES, L. A.. Metais pesados em milho fertilizado com fosfato natural e composto de lodo de esgoto. Revista Brasileira de Engenharia Agrícola e Ambiental, v.15, n.10, p.1082-1088, 2011. DOI: http://doi.org/10.1590/S1415$\underline{43662011001000013}$

JUNIO, G. R. Z.; SAMPAIO, R. A.; NASCIMENTO, A. L.; SANTOS, G. B.; SANTOS, L. D. T.; FERNANDES, L. A.. Produtividade de milho adubado com composto de lodo de esgoto e fosfato natural de Gafsa. Revista Brasileira de Engenharia Agrícola e Ambiental, v.17, n.7, p.706-712, 2013. DOI: http://doi.org/10.1590/S1415$\underline{43662013000700003}$

KITAMURA, A. E.; ALVES, M. C.; SUZUKI, L. G. A. S.; GONZALEZ, A. P.. Recuperação de um solo degradado com a aplicação de adubos verdes e lodo de esgoto. Revista Brasileira de Ciência do Solo, v.32, p.405-416, 2008. DOI: http://doi.org/10.1590/S0100-06832008000100038

LATARE, A. M.; KUMAR, O.; SINGH, S. K.; GUPTA, A.. Direct and residual effect of sewage sludge on yield, heavy metals contente and soil fertility under rice-wheat system.

Ecological Engineering, v.69, p.17-24, 2014.
LEMAINSKI, J.; SILVA, J. E.. Avaliação agronômica e econômica da aplicação de biossólido na produção de soja. Pesquisa Agropecuária Brasileira, v.41, p.1477- 1484, 2006. DOI: http://doi.org/10.1590/S0100-204X2006001000004

MACIEL, C. A. C.; SANTOS, A. B. C. R.; ANTÔNIO, F. R.; DUARTE, F. C.; FILHO, M. M.. Reutilização do lodo ETE industrial na cultura de mudas de feijão. Espírito Santo do Pinhal: UNIPINHAL, 2009.

MELO, V. P.; BEUTLER, A. N.; SOUZA, Z. M.; CENTURION, J. F.; MELO, W. J.. Atributos físicos de Latossolos adubados com biossólido. Pesquisa Agropecuária Brasileira, v.39, p.67-72, 2004. DOI: http://doi.org/10.1590/S0100204X2004000100010

MELO, W. J.; MARQUES, M. O.. Potencial do lodo de esgoto como fonte de nutrientes para as plantas. In: BETTIOL, W.; CAMARGO, O. A.. Impacto ambiental do uso agrícola do lodo de esgoto. Jaguariúna: EMBRAPA Meio Ambiente, 2000.

METCALF, L.; EDDY, H. P.. Wastewater engineer treatment disposal, reuse. 4 ed. New York: Hill Book, 2003.

MAGUIRE, J. D.. Speed of germination-aid in selection and evaluation for seedlings emergence and vigor. Crop Science, v.2, n.1, p.176-177, 1962. DOI: http://doi.org/10.2135/cropsci1962.0011183X00020002003 $\underline{3 x}$

NASCIMENTO, C. W. A.; BARROS, D. A. S.; MELO, E. E. C.; OLIVEIRA, A. B.. Alterações químicas em solos e crescimento de milho e feijoeiro após aplicação de lodo de esgoto. Revista Brasileira de Ciência do Solo, v.28, p.385-392, 2004. DOI: http://doi.org/10.1590/S0100-06832004000200017

NASCIMENTO, A. L.; SAMPAIO, R. A.; ZUBA, G. R.; JUNIO, J. P. C.; FERNANDES, L. A.; RODRIGUES, M. N.. Teores de metais pesados no solo e em girassol adubado com lodo de esgoto. Revista Brasileira de Engenharia Agrícola e Ambiental, v.18, n.3, 294-300, 2014. DOI: http://doi.org/10.1590/S1415-43662014000300008

NOGUEIRA, T. A. R.; OLIVERIA, L. R.; MELO, W. J.; FONSECA, I. M.; MELO, G. M. P.; MELO, V. P.; MARQUES, M. O.. Cádmio, cromo, chumbo e zinco em plantas de milho e em latossolo após nove aplicações anuais de lodo de esgoto. Revista Brasileira de Ciência do Solo, v.32, p.195-207, 2008. DOI: http://doi.org/10.1590/S0100-06832008000500040

PEDROZA, M. M.; VIEIRA, G. E. G.; SOUSA, J. F.; PICKLER, A. C.; LEAL, A. C.; MILHOMEN, C. C.. Produção e Tratamento de lodo de esgoto: uma revisão. Revista Liberato, v.11, n.16, 89-188, 2010. DOI: http://doi.org/10.1590/S0100$\underline{06832008000500040}$

QUINTANA, N. R. G.; CARMO, M. S.; MELO, W. J.. Lodo de esgoto como fertilizante: produtividade agrícola e rentabilidade econômica. Nucleus, v.8, n.1, 183-191, 2011. DOI: http://doi.org/10.3738/1982.2278.527

SILVA, F. C.. Uso de resíduos orgânicos na agricultura. In: SANTOS, G. A.; SILVA, L. Z.; CANELLAS, L. P.; CAMARGO, F. A. O.. Fundamentos da matéria orgânica do solo: Ecossistemas tropicais e subtropicais Porto Alegre: Metrópole, 2008, 
p.597-624.

SOUZA, M. F. P.; BEM, E. A. D.; DALCHIAVON, F. C.; YOSHITOME, M. Y.; ALVES, M. C.. Propriedades físicas de um latossolo vermelho tratado com lodo de esgoto. Engenharia Ambiental: Pesquisa e Tecnologia, v.9, n.3, p.27-40, 2012.

SUCIU, N. A.; LAMASTRA, L.; TREVISAN, M.. PAHs contente os sewage sludge in Europe and its use as soil fertilizer. Waste Management, v.41, p.119-127, 2015. DOI: http://doi.org/10.1016/j.wasman.2015.03.018

TAMANINI, C. R.; MOTTA, A. C. V.; ANDREOLI, C. V.; DOETZER, B. H.. Land reclamation recovery with the sewage sludge use. Brazilian Archives of Biology and Technology, v.51, n.4, p.643-655, 2008. DOI:

http://doi.org/10.1590/S1516-89132008000400023

TRANNIN, I. C. B.; SIQUEIRA, J. O.; MOREIRA, F. M. S.. Avaliação agronômica de umbiossólido industrial para a cultura do milho. Pesquisa Agropecuária Brasileira, v.40, n.3, p.261-269, 2005. DOI: http://doi.org/10.1590/S0100$\underline{204 \times 2005000300010}$

TRIGUEIRO, R. M.; GUERRINI, I. A.. Utilização de lodo de esgoto na produção de mudas de aroeirapimenteira. Revista Árvore, v.38, n.4, p.657-665, 2014. DOI: http://doi.org/10.1590/S0100-67622014000400009

TSUTIYA, M. T.. Alternativas de disposição final de biossólidos. In: TSUTIYA, M. T.. Biossólidos na Agricultura. São Paulo: SABESP, 2001.

ZOMER, J. A.; ELY, C.; COMELLI, R. U.; ALVES, M. V.; SKORONSKI, E.. Lodo de estação de tratamento de esgoto como fertilizante no cultivo de fumo e aveia. Revista em Agronegócio e Meio Ambiente, v.11, n.1, p.185-201, 2018. DOI: $\underline{\text { http://dx.doi.org/10.17765/2176- }}$ 9168.2018v11n1p185-201

A CBPC - Companhia Brasileira de Produção Científica (CNPJ: 11.221.422/0001-03) detém os direitos materiais desta publicação. Os direitos referem-se à publicação do trabalho em qualquer parte do mundo, incluindo os direitos às renovações, expansões e disseminações da contribuição, bem como outros direitos subsidiários. Todos os trabalhos publicados eletronicamente poderão posteriormente ser publicados em coletâneas impressas sob coordenação da Sustenere Publishing, da Companhia Brasileira de Produção Científica e seus parceiros autorizados. Os (as) autores (as) preservam os direitos autorais, mas não têm permissão para a publicação da contribuição em outro meio, impresso ou digital, em português ou em tradução. 